\title{
EFFECT OF NUMBER OF ROTOR POLES ON AC LOSSES OF PERMANENT MAGNET MACHINES HAVING TWO SEPARATE STATORS
}

\author{
C. C. Awah ${ }^{1, *}$ and O. I. Okoro ${ }^{2}$ \\ 1,2 Dept. of Electrical \& Electronics EnGr., Michael OKPara Univ. of Agric, Umudike, ABia State, NiGERIA \\ E-mail addresses:1cawah@ieee.org, ${ }^{2}$ profogbonnayaokoro@ieee.org
}

\begin{abstract}
A study on permanent magnet (PM) eddy current and core losses of dual-stator PM machines is investigated in this paper. The analyzed core losses include: the rotor core loss, stator core loss and the total core loss of the machines. Further, the effect of their different rotor pole number is also presented with quantitative comparison. Due to the relatively high electrical frequency of the analyzed 14-rotor pole machine, it gives the largest amount of PM eddy current loss. Similarly, the 13-pole machine exhibits the largest amount of total core loss amongst the compared machines. Although, the investigated machine having 4-rotor pole has a low core loss value, likely due to its low electrical frequency. However, it has the poorest efficiency amongst all, due to its very low output torque. Overall, largest torque density is obtained in the 13-pole machine at rated current condition.
\end{abstract}

Keywords: core loss, efficiency, PM eddy current loss, PM flux linkage, power and torque

\section{INTRODUCTION}

Since the efficiency of electrical machines is largely dependent on their losses, therefore, it is needful for machine designers to analyze the core and permanent magnet (PM) eddy current losses on the machines in order to have accurate prediction of its overall performance.

Chunting et al in [1], proved that by employing appropriate design of magnet shapes as well as the use of optimal slot opening could reduce the eddy current and core loss of a given PM machine. Moreover, by adopting suitable number of stator/rotor pole combination, the core loss of the machines could be well mitigated [1, 2]. This assertion is further strengthened in [3]. Similarly, it is proven in [4], that the higher the number of slots of synchronous reluctance machine which is a permanent magnetassisted machine, the lower the amount of its rotor losses. More so, the wider the slot opening the higher the amount of rotor losses in the machine. Thus, closedslot machines are preferred choice in rotor loss reduction as demonstrated in [4]. However, the considered machine in this study has an open-slot structure.

More importantly, due to the varying nature of the magneto motive force (MMF) harmonic order and waveforms in the air gap, the size of air-gap of a given electric machine greatly affects its loss contents. More so, the machines having concentrated tooth windings generally have more eddy current losses than their equivalents with other types of winding configurations as stated in [2]. Similarly, it is noted in [3] that, despite the admirable qualities of fractional-slot PM machines in terms of high performance, it is usually associated with large amount of rotor induced eddy current losses owing to its large amount of spatial harmonic contents. The percentage of eddy current loss in PM machines could be reduced by employing PM segmentation technique. In particular, significant eddy current loss reduction could be achieved in surface-mounted permanent magnet (SPM) machines by partitioning the magnets into smaller parts in either radial or circumferential direction. However, this may lead to an increased magnitude of rotor core loss especially for non-laminated cores [5]. Further loss reduction could also be realized in concentrated-wound machines by the use of stator segment having equal tooth-width including the unwound auxiliary middle-tooth as illustrated in [6]. However, this will lead to reduced output torque when compared to concentrated-wound machine whose stator segment is made of unequal stator-tooth-width.

Furthermore, a study on loss estimation of synchronous reluctance machines i.e. PM-assisted 
synchronous machines given in [7] which is validated by experiment, shows that it is preferable to laminate the rotor core of such machines in the radial direction instead of axially due to the large core and eddy current losses associated with the later. Although, the cup-rotor of the predicted machine in this work is considered as core without laminations; nevertheless, further loss reduction is feasible when calculated as laminated core. Moreover, it is shown by [8] that the use of epoxy material in the retaining sleeves of surface-mounted permanent magnet machines having rotor-PM configuration under high speed operation could help in reducing the attendant rotor losses in such machines extensively. In this paper, the core loss and eddy current losses in PM machine having two separate stators with different number of rotor poles is investigated.

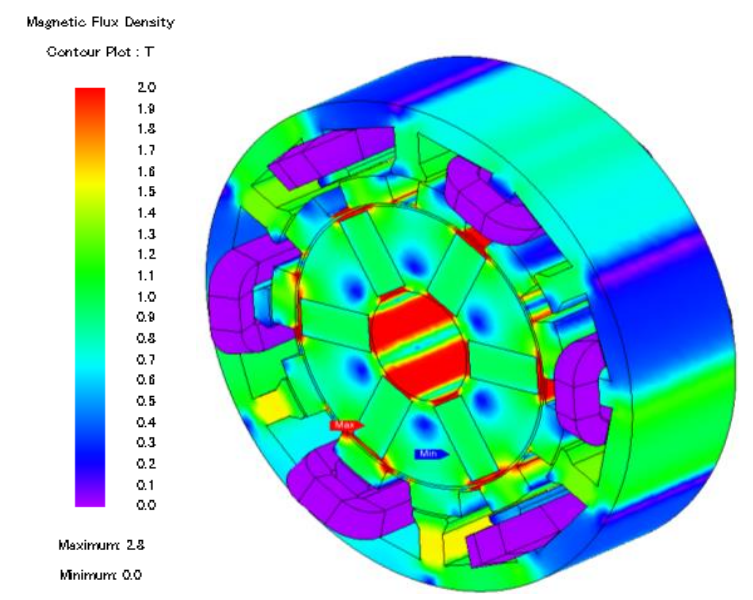

Figure 1: Open-circuit flux-density of the analysed machine.

Figure 1 shows the 3D-FEA open-circuit flux-density distribution of the developed machine. Finite element analysis (FEA) is used in predicting the results in this work. It is worth noting that, the developed machine has an outer diameter of $90 \mathrm{~mm}$ with active stack length of $25 \mathrm{~mm}$.

\section{METHODOLOGY}

The analysed machine in this work is modelled and simulated with two-dimensional finite element analysis (FEA) software at rated current of $15 \mathrm{~A}$, as well as on a fixed copper loss of $30 \mathrm{~W}$ at different operating speed. However, separate/additional no-load calculation was performed on a 3D model to obtain the open-circuit flux density distribution of the analysed machine. The estimated core losses of the developed PM machine is predicted using the Steinmetz loss equation given in (1).

$$
P_{\text {loss }}=K_{h} B_{m}^{2} f+K_{e}\left(B_{m} f\right)^{1.5}+K_{c}\left(B_{m} f\right)^{2}
$$

In (1), where $B_{m}$ is the peak value of the magnetic flux density, $f$ is the frequency; $K_{h}, K_{\Theta}$ and $K_{c}$ are the loss coefficients for hysteresis, excess and eddy current losses, respectively.

Moreover, the loss constants are same with that obtained in [9]. Note that, the PM rare earth material used in this paper is the Neodymium Iron Boron $(\mathrm{NdFeB})$. Furthermore, the data on the relationship between the magnetic flux density, $B(\mathrm{~T})$ and the magnetic field strength, $H(\mathrm{AT} / \mathrm{m})$ used in this work is expressed by equation (2) and listed in Table 1 , in accordance with [10]. The $B$ - $H$ curve values in Table 1 are inputted in the material set-up section of the finite element solver to account for the nonlinear relative permeability of the steel material and thus, obtain the magnetic field solution.

$$
B=\mu H
$$

In (2) where $\mu$ is the magnetic permeability of the material. The optimized parameters of the analysed machine having different rotor poles are listed in Table 2.

\section{LOSS PROFILE}

The magnet eddy current losses of the machines are depicted in Figure 2. Obviously, the machines with high rotor-pole numbers (13-poleand 14-pole in particular) exhibit higher magnet eddy current loss, due to high electrical frequency.

The rotor and stator core losses of the analysed machines are given in Figures 3 and 4, respectively. Moreover, the total core losses of the machines at rated current is shown in Figure 5. The results show that the 13-pole machine is characterised by the highest amount of core loss, while the least amount of core loss is seen in the 4-pole machine.

Table 1: The Data of B-H Curve

\begin{tabular}{cccc}
\hline$H(\mathrm{AT} / \mathrm{m})$ & $B(\mathrm{~T})$ & $H(\mathrm{AT} / \mathrm{m})$ & $B(\mathrm{~T})$ \\
\hline 0 & 0 & 3183 & 1.52 \\
22.28 & 0.05 & 4774.6 & 1.58 \\
25.46 & 0.1 & 6366.1 & 1.63 \\
31.83 & 0.15 & 7957.7 & 1.67 \\
47.74 & 0.36 & 15915 & 1.8 \\
63.66 & 0.54 & 31830 & 1.9 \\
79.57 & 0.65 & 11407 & 2 \\
159.15 & 0.99 & 190984 & 2.1 \\
318.3 & 1.2 & 350138 & 2.3 \\
477.46 & 1.28 & 509252 & 2.5 \\
636.61 & 1.33 & 560177.2 & 2.563994 \\
795.77 & 1.36 & 1527756 & 3.77989 \\
1591.5 & 1.44 & N/A & N/A \\
\hline
\end{tabular}

Source: The electrical machines and drives research group (EMD), the University of Sheffield, UK.

$(N / A=$ not applicable $)$. 
Table 2: Optimized Machine Parameters

\begin{tabular}{lllllllll}
\hline Number of rotor poles & 4 & 5 & 7 & 8 & 10 & 11 & 13 & 14 \\
\hline Number of phases & 3 & & & & & & & \\
Magnet remanence (T) & 1.2 & & & & & & & \\
Relative permeability & 1.05 & & & & & & & \\
Number of turns/phase & 72 & & & & & & & \\
Outer stator diameter (mm) & 90 & & & & & & & \\
Airgap length (mm) & 0.5 & & & & & & & \\
Axial length (mm) & 25 & & & & & & & \\
Split ratio & 0.66 & 0.68 & 0.71 & 0.68 & 0.67 & 0.68 & 0.70 & 0.71 \\
Slot opening/slot pitch ratio & 0.53 & 0.40 & 0.42 & 0.53 & 0.60 & 0.64 & 0.58 & 0.55 \\
Rotor radial thickness (mm) & 5.66 & 5.48 & 6.03 & 5.68 & 4.91 & 4.15 & 4.18 & 3.84 \\
PM thickness (mm) & 9.68 & 7.95 & 7.92 & 9.32 & 8.15 & 7.82 & 8.40 & 8.13 \\
Stator back-iron thickness (mm) & 4.46 & 4.61 & 4.49 & 4.11 & 4.37 & 4.64 & 4.93 & 5.10 \\
\hline
\end{tabular}

Table 3: Losses and Efficiency of Analysed Machines

\begin{tabular}{lcccc}
\hline Rotor pole No, $N_{I}$ & 4 & 5 & 7 & 8 \\
\hline$P_{E M}(\mathrm{~W})$ & 529.97 & 668.33 & 757.25 & 798.13 \\
$p_{\text {iron }}(\mathrm{W})$ & 29.63 & 26.47 & 28.12 & 26.13 \\
$p_{P M}(\mathrm{~W})$ & 2.93 & 1.14 & 1.05 & 1.41 \\
$\eta(\%)$ & 89.44 & 92.06 & 92.75 & 93.28 \\
Rotor pole No, $N_{r}$ & 10 & 11 & 13 & 14 \\
$P_{E M}(\mathrm{~W})$ & 955.02 & 870.10 & 681.11 & 645.45 \\
$p_{\text {iron }}(\mathrm{W})$ & 31.07 & 27.19 & 21.53 & 27.65 \\
$p_{P M}(\mathrm{~W})$ & 2.18 & 2.10 & 2.76 & 7.09 \\
$\eta(\%)$ & 93.79 & 93.62 & 92.62 & 90.88 \\
\hline
\end{tabular}

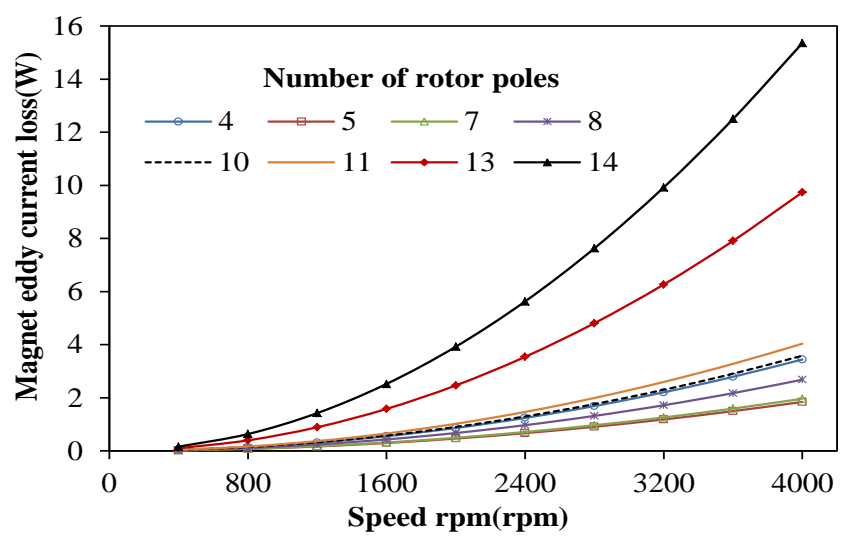

Figure 2: Variation of PM eddy current loss with speed, $I=15 A$.

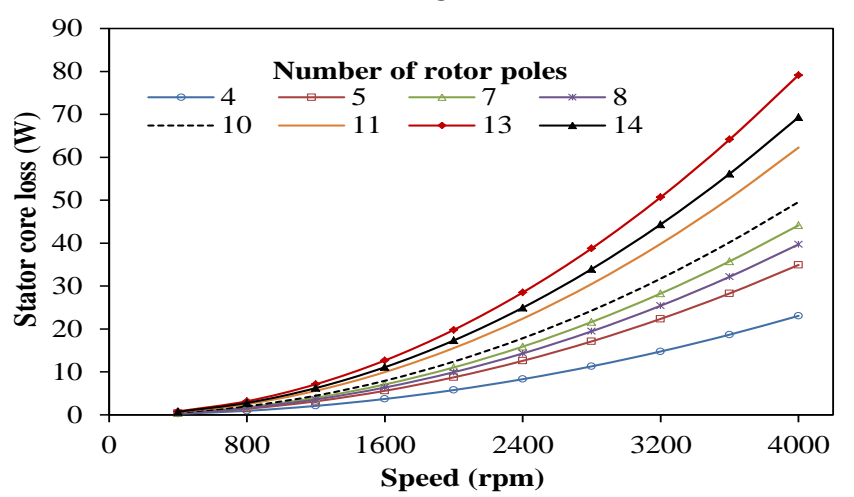

Figure 4: Variation of stator core loss with speed, $I=15 \mathrm{~A}$.
Furthermore, a comparison of the PM eddy current loss, the rotor core loss, the stator core loss and the total core loss of the analysed machines at high speed (4000rpm) are illustrated in Figure 6. Overall, the high pole machines have larger PM eddy current losses than the low pole ones, due to their relatively high frequency. Note that, the values of PM eddy current and core losses of the compared machines at fixed copper loss condition of $30 \mathrm{~W}$ are obtained at 2000rpm and listed in Table 3; where $P_{E M}$, $p_{\text {iron }}$ and $p_{P M}$ are the electromagnetic power, core loss and PM eddy current loss, respectively.

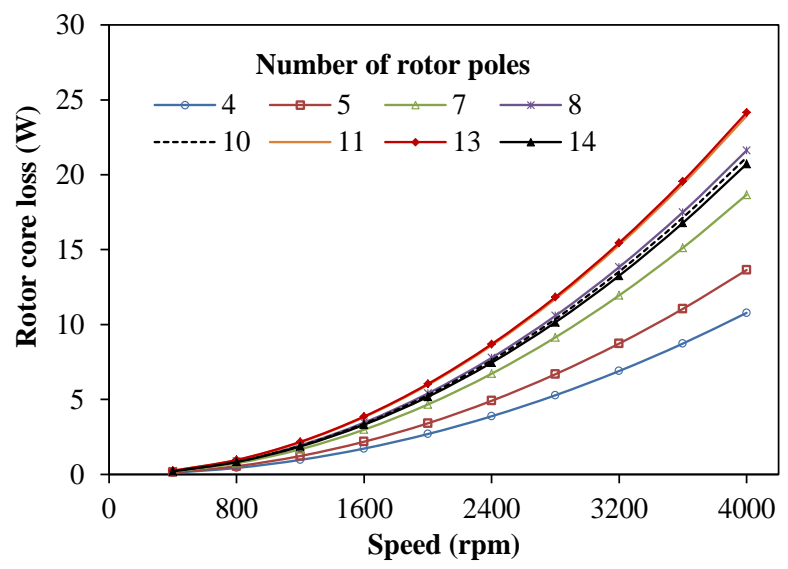

Figure 3: Variation of rotor core loss with speed, $I=15 \mathrm{~A}$.

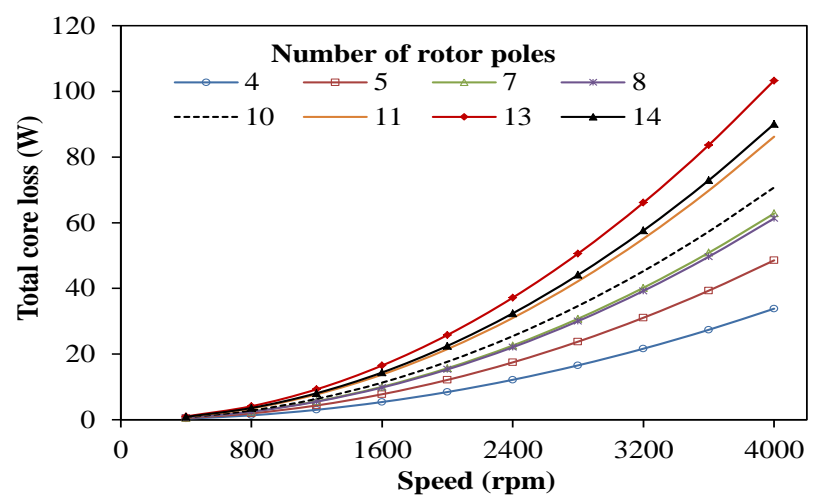

Figure 5: Variation of total core loss with speed, $I=15 \mathrm{~A}$. 
The output power is given in terms of output torque in equation (3), whereas the efficiency, $\eta$, of the machine is stated in equation (4).

$$
P_{\text {out }}=T_{e} \times \omega
$$

In (3) $P_{\text {out }}, T_{e}$ and $\omega$ are the output power (W), electromagnetic torque $(\mathrm{Nm})$ and rotor speed (rpm), respectively

$$
\eta=\frac{P_{\text {out }}}{P_{\text {in }}} \times 100 \%=\frac{P_{\text {out }}}{P_{\text {out }}+\text { losses }} \times 100 \%
$$

The efficiencies of the analysed machines at fixed copper loss (30W) are compared in Figure 7 and also listed in Table 3. Better efficiency is obtained in the machines having $N_{I}=10$ and 11.It should be noted that, the high rotor pole machines have larger electromagnetic torque than the low-pole ones. Thus, this influences the overall efficiency of the machine, irrespective of their loss values; since the output power of an electric machine is a function of its torque and rotational speed. The computed electromagnetic torque, $T$, of the analysed machine is given in (5).

$$
T=1.5 N_{r}\left[\psi_{P M} I_{q}+\left(L_{d}-L_{q}\right) I_{d} I_{q}\right]
$$

In (5), $N_{r}$ is the number of rotor poles. $\psi_{P M}$ is the PM flux-linkage. $I_{d}, I_{q}$ and $L_{d}, L_{q}$ are the direct- and quadrature-axis currents and inductances, respectively. The basic performance such as inductance and fluxweakening profile of the developed machine is listed in Table 4.

The permanent magnet flux-linkages of the analysed machines under different load currents are displayed in Figure 8. It should be noted that the flux-linkage decreases as the current increases, owing to magnetic saturation. Similarly, the torque- and power-speed curves of Figure 9 show that, the machines having thirteen and eleven number of rotor poles have larger output torque at maximum current and voltage of $15 \mathrm{~A}$ and $22.9 \mathrm{~V}$, respectively, amongst the compared machines.

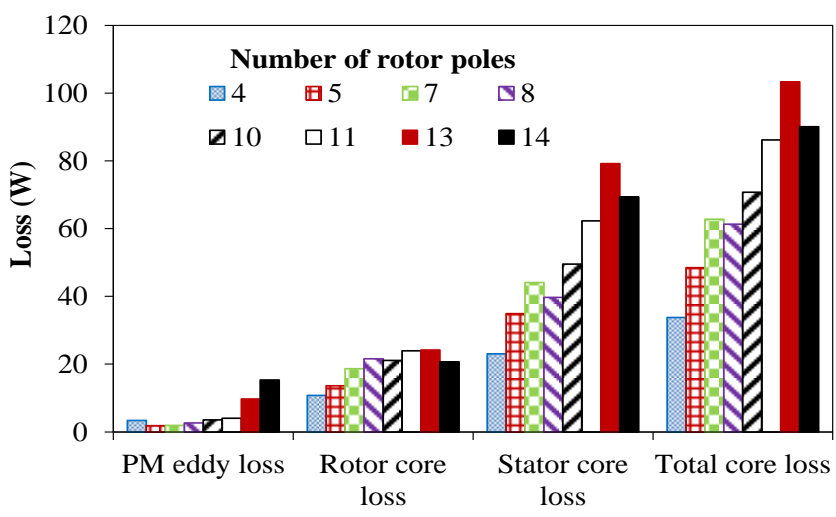

Figure 6: Comparison of losses (I=15A, 4000rpm).

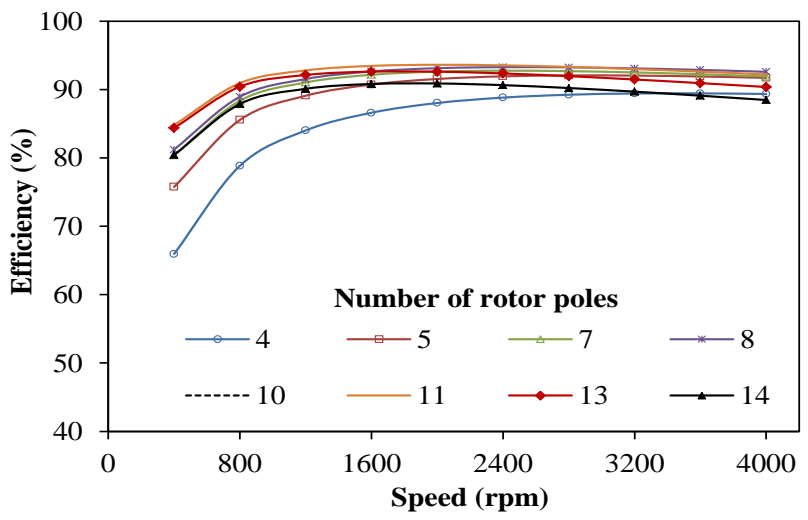

Figure 7: Comparison of efficiency, copper loss $=30 \mathrm{~W}$.

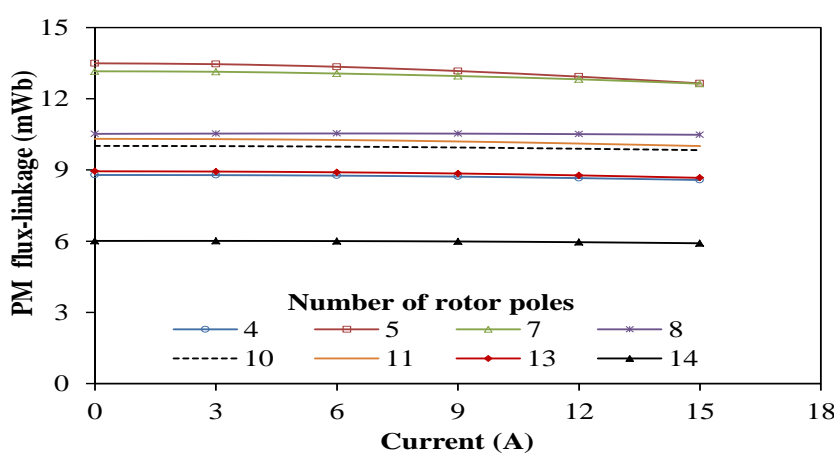

Figure 8: Variation of PM flux-linkages against $q$-axis current, $i_{d}=0$.

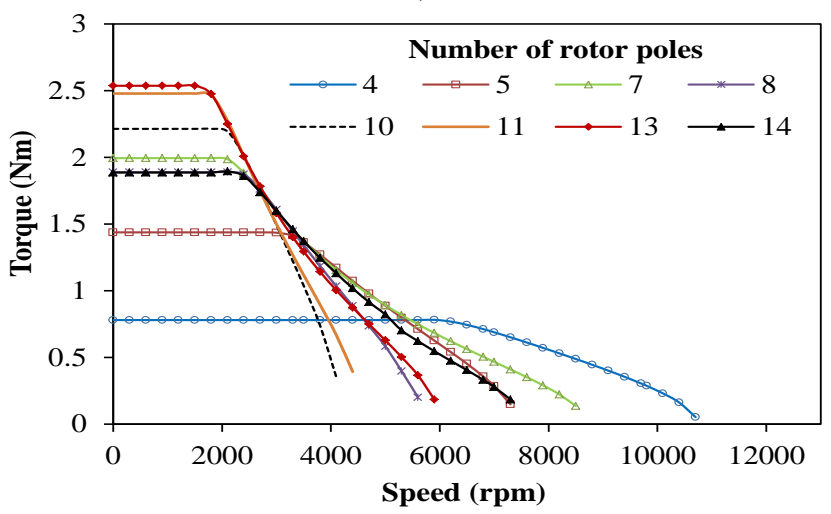

(a) Torque versus speed

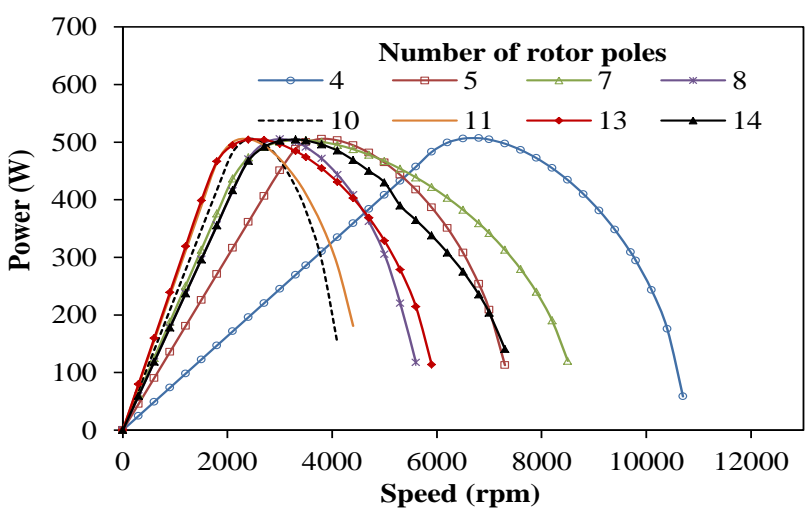

(b) Power versus speed

Figure 9: Comparison of torque/power-speed characteristics. 
Table 4: Flux Weakening and Inductance Potentials

\begin{tabular}{lcccc}
\hline Rotor pole number, $N_{r}$ & 4 & 5 & 7 & 8 \\
\hline$D$-axis inductance, $L_{d}(\mathrm{mH})$ & 0.20 & 0.36 & 0.56 & 0.36 \\
$Q$-axis inductance, $L_{q}(\mathrm{mH})$ & 0.29 & 0.49 & 0.49 & 0.38 \\
PM flux (mWb) & 8.79 & 13.50 & 13.16 & 10.52 \\
$K_{f w}$ & 0.34 & 0.4 & 0.64 & 0.51 \\
Base speed (rpm) & 5600 & 2900 & 2000 & 2200 \\
Maximum speed (rpm) & 10700 & 7400 & 8600 & 5700 \\
Max. speed / base speed & 1.91 & 2.55 & 4.3 & 2.59 \\
Maximum power $(\mathrm{W})$ & 507.25 & 505.75 & 503.56 & 505.40 \\
Torque density $\left(\mathrm{kNm} / \mathrm{m}^{3}\right)$ & 8.84 & 14.33 & 18.94 & 19.97 \\
Rotor pole number, $N_{r}$ & 10 & 11 & 13 & 14 \\
$D$-axis inductance, $L_{d}(\mathrm{mH})$ & 0.29 & 0.35 & 0.35 & 0.23 \\
$Q$-axis inductance, $L_{q}(\mathrm{mH})$ & 0.31 & 0.37 & 0.37 & 0.32 \\
PM flux $(\mathrm{mWb})$ & 10.01 & 10.31 & 8.95 & 6.01 \\
$K_{f w}$ & 0.43 & 0.51 & 0.59 & 0.57 \\
Base speed $(\mathrm{rpm})$ & 1900 & 1700 & 1600 & 2000 \\
Maximum speed $(\mathrm{rpm})$ & 4200 & 4500 & 6000 & 7500 \\
Max. speed / base speed & 2.21 & 2.65 & 3.75 & 3.75 \\
Maximum power $(\mathrm{W})$ & 505.38 & 505.78 & 505.15 & 504.61 \\
Torque density $\left(\mathrm{kNm} / \mathrm{m}^{3}\right)$ & 23.89 & 26.12 & 25.56 & 19.38 \\
\hline
\end{tabular}

\section{CONCLUSION}

Permanent magnet eddy current and core losses of PM machines having different excitation stators as well as different rotor pole numbers is investigated. The analysis reveal that, the best efficiency is given by the machine having ten-rotor-pole and eleven-rotor-pole numbers while the four-rotor-pole machine gives the least efficiency value, although it exhibits the lowest core loss value due to its poor output torque. It is also observed that, the highest amount of PM eddy current loss is obtained in the fourteen-pole machine due to its relatively high electrical frequency. Moreover, the eleven- and thirteen-pole machines have good output torque performance.

\section{ACKNOWLEDGEMENT}

The first author would like to thank the Commonwealth Scholarship Commission, UK for the sponsorship to run a $\mathrm{PhD}$ programme at the University of Sheffield, UK, during which period this research was carried out.

\section{REFERENCES}

[1] C. C. Mi, G. R. Slemon, and R. Bonert, "Minimization of iron losses of permanent magnet synchronous machines," IEEE Trans. Energy. Convers., vol. 20, no. 1, pp. 121-127, Mar. 2005.

[2] M. Nakano, H. Kometani, and M. Kawamura, "A Study on eddy-current losses in rotors of surface permanent-magnet synchronous machines," IEEE Trans. Ind. Appl., vol. 42, no. 2, pp. 429-435, Mar./Apr. 2006.
[3] N. Bianchi, and E. Fornasiero, "Impact of MMF space harmonic on rotor losses in fractional-slot permanent-magnet machines," IEEE Trans. Energy. Convers., vol. 24, no. 2, pp. 323-328, Jun. 2009.

[4] H. Hofmann, and S. R. Sanders, "High-speed synchronous reluctance machine with minimized rotor losses," IEEE Trans. Ind. Appl., vol. 36, no. 2, pp. 531-539, Mar./Apr. 2000.

[5] P. Sergeant, and A. V. Bossche, "Segmentation of magnets to reduce losses in permanent-magnet synchronous machines," IEEE Trans. Magn., vol. 44, no. 11, pp. 4409-4412, Nov. 2008.

[6] G. J. Atkinson, B. C. Mecrow, A. G. Jack, D. J. Atkinson, P. Sangha, and M. Benarous, "The analysis of losses in high-power fault-tolerant machines for aerospace applications," IEEE Trans. Ind. Appl., vol. 42, no. 5, pp. 1162-1170, Sept./Oct. 2006.

[7] I. Scian, D. G. Dorrell, and P.J. Holik, "Assessment of losses in a brushless doubly-fed reluctance machine," IEEE Trans. Magn., vol. 42, no. 10, pp. 3425-3427, Oct. 2006.

[8] H.W. Cho, S. M. Jang, and S.K. Choi, "A design approach to reduce rotor losses in high-speed permanent magnet machine for turbocompressor," IEEE Trans. Magn., vol. 42, no. 10, pp. 3521-3523, Oct. 2006.

[9] Y. Pang, Z. Q. Zhu, D. Howe, S. Iwasaki, R. Deodhar, and A. Pride, "Investigation of iron loss in fluxswitching PM machines", in Proc. of Power Electro. Mach. and Dri. (PEMD), pp.460-464, 2008.

[10] Chapman, S. J. Electric Machinery Fundamentals, McGraw-Hill, New York, Fifth Edition, 2012. 